\title{
Reassembling the Indigenous Public Sphere
}

\section{Jack Latimore}

University of Melbourne

latimore.j@unimelb.edu.au

\section{David Nolan}

University of Melbourne

\section{Margaret Simons}

University of Melbourne

\section{Elyas Khan}

University of Melbourne

\section{Abstract}

This paper seeks to provide an initial theoretical grounding to assess a practical project: a new software application that attempts to be a beneficial resource in the field of Indigenous representation. As a starting point, we are concerned to provide a theoretical ground for considering the inherited and shifting spaces of Indigenous media representation. To this end, this paper reconsiders the strengths and weaknesses of debates surrounding the 'Indigenous public sphere'. This is used as grounds for critically understanding the relations that constitute this field. Following this, we consider how a more materialist approach to publics might enable a productive reconceptualization, and in particular how digital media initiatives and shifting news markets may be contributing to change. Finally, drawing on this model, we outline both the 'Wakul app' project, and how this framework might inform an assessment of its impact.

Keywords: Indigenous media; Public Sphere; Activism; Amplification; Social Media; Representation

\section{Introduction}

Critical work that has focussed on news media representations of Indigenous people and issues has focused on a number of profound shortcomings. Across numerous studies, it has been found that Indigenous people are positioned as a 'problem population'. Issues facing Indigenous communities have relied on a narrow range of frames and voices, and discourses of deficit and blame. While such findings should not be dismissed, there is a risk that critical perspectives might, albeit inadvertently, tend to position issues facing Indigenous people as unchanging and intractable, by positioning the field of representation as overly static (Cottle 2000: 9). In recent years digital transformations have precipitated 'crises' within, and reconfigurations of, mass media markets that have resulted in both new players and altered relations with audience-users (Simons 2013; Lewis 2012). At the same time, the rise of networked ICTs and social media platforms have provided new opportunities for both 'mass self-communication' (Castells 2009) through peer-to-peer networks, and for collective, networked media initiatives that leverage off the popularity and affordances of platforms such as Twitter and Facebook. As numerous studies have noted, Indigenous Australians have been strong adopters of new digital media communication technologies, leading to a proliferation of Indigenous voices online (Carlson and Frazer, 2015; McNair Ingenuity Research 2014; Waller et al 2015, Sweet et al 2013; Lumby 2011). More Indigenous people now choose to be informed about the issues and events that affect them via digital media channels and sources, and may bypass more traditional media outlets altogether. Such adoption, as we discuss below, has also contributed to a proliferation of Indigenous news outlets that are now covering issues and events that previously were not reported at all by the mainstream media.

In light of such transformation, it is timely to reconsider extant conceptualisations of the space of Indigenous media representation. To this end, we begin this article by reconsidering the concept of the 'Indigenous public sphere'. As we go on to discuss, this has previously been 
elaborated in two distinct and contrasting ways. On one hand, the Indigenous public sphere is positioned as a space of Indigenous media production that is separate from, and provides a significant critical counterpoint to, mass media produced by non-Indigenous individuals and organisations. In this conception, the Indigenous public sphere acts as a 'counter-public' that is distinct from and significantly contests the ways in which Indigenous people and issues are reported and discussed in 'mainstream media'. On the other hand, the Indigenous public sphere has also been positioned as a wider sphere of representation, where patterned but heterogeneous ideas and images of Indigeneity are produced and circulated across a broader (usually national) space by both Indigenous and non-Indigenous actors. By contrasting the work of Hartley and McKee (2000) and Meadows (2005), we begin this article by critically comparing and contrasting these traditions. In doing so, we not only consider their respective strengths and possible weaknesses, but also how both share a tendency to conceptualise the public sphere as a space of dialogue and speech. While this usefully foregrounds issues of voice and representation, we argue that it can tend to problematically underplay more prosaic, material processes and practices through which publics are 'made' (Latour, 2005). By adopting a materialist focus that draws on the tenets of Actor Network Theory (ANT), we move to consider the potential contribution of a particular media intervention, the Wakul app, that seeks to use digital media affordances to improve Indigenous media access and representation.

\section{Reconsidering the Indigenous Public Sphere}

In an overview of research on representations of Indigenous people and issues, McCallum and Waller (2017, forthcoming) note that the majority of research tended to mount (or provide evidence to support) a critique of 'media racism'. Such work has focused critically and analytically on how media coverage and reporting practices serve to sustain racist ideologies, and has repeatedly found that routine journalism practices result in portrayals of Indigenous people and issues as a source of conflict, blame and deficit (Due and Riggs, 2011; Meadows, 2001; Brough, 1999; Ewart, 1997; Jakubowicz, 1994; Cunneen, 1992). Such representations contribute to an environment that produces negative social and health outcomes for Indigenous people, both directly and in their contribution to the process of developing and implementing policy (Stoneham et al 2014, McCallum 2011, Paradies et al 2008). In summarising the findings of a wide range of relevant studies, McCallum and Waller conclude:

...news reporting overwhelmingly represents Indigenous Australians as a source of societal risk and as problematic for the mainstream; Indigenous policy is generally only of interest when it meets a narrow range of news values - most importantly conflict and proximity to political elites; and the media construct Indigeneity as deviance and privilege news values of conflict and otherness (McCallum and Waller 2017, forthcoming).

While the concept of an 'Indigenous public sphere' does not necessarily exclude such critical perspectives, it nevertheless stands in partial contrast to them. Work that focuses on media racism tends to critique the role of mainstream media as perpetuating power relations underpinned by racial inequality. The model of the public sphere, by contrast, tends to be mobilized as a (implicitly or explicitly) normative concept, and a (actual or potential) space of inclusive, democratic debate. In his celebrated (and much critiqued) account of the bourgeois public sphere and its subsequent structural transformation, Habermas (1989) presented the public sphere as both a basis for describing actual spaces of public debate and simultaneously as a normative critical ideal. This conflation has been strongly criticised for its tendency to result in an overly idealised account, that underplays the degree to which mechanisms of exclusion, as well as principles of inclusion, structured to bourgeois public sphere (see Thompson 1995; Fraser 1992; Eley 1992). Nevertheless, the Indigenous public sphere inherits a tendency to position the public sphere simultaneously as an actual space of communication (the actually existing public sphere) and as something that refers to an ideal or aspirational model of democratic communication. 
The use of the public sphere approach as an alternative to critiques of media racism is most strongly articulated by Hartley and McKee (2000), who announce that their project is 'an attempt to re-theorize the field' that stands in contrast to 'previous work [that] has often concentrated on finding examples of racist or 'negative' coverage' (2000: 1). In contrast to such 'negative' findings, Hartley and McKee present a more optimistic perspective, in which the Indigenous public sphere is presented as moving increasingly towards a more 'dialogic' model. In this model, the public sphere is conceived as a space that does not simply reflect 'the public' as an externally existing population. Rather, by enabling the formation and exchange of 'public opinion' and 'public imagery', it is through the public sphere of media representations that conceptions of collective identity, and the role played by Indigeneity within it, are negotiated by Indigenous and non-Indigenous Australia. The 'Indigenous public sphere', in this definition, does not refer solely to the space of news, but rather to the entire semiotic space in which images and conceptions of Indigeneity are produced and circulated through various (non-Indigenous and Indigenous) media. The Indigenous public sphere is thus also not entirely, or even primarily, the preserve of Indigenous participants. Indeed, Hartley and McKee comment that " $[t]$ hus far, the Indigenous public sphere has hardly been under the control of Indigenous people" (2000: 6). Nevertheless, they strongly emphasise that Indigenous people are "far from passive recipients of media representations", for they "are themselves media producers, and are active participants in the processes of media production, dissemination, regulation, reception and innovation" (2000: 6).

This framework draws on and reproduces aspects of Hartley's earlier theorisation of the feminist public sphere (Hartley 1996), in which he emphasised the degree to which feminist publics not only create their own 'counter-public' spaces of dialogue, but have successfully sought to both challenge and gain access to the wider public sphere, such that the latter both represents and contributes to the negotiation of a feminist identity politics. Hartley explicitly notes that a feminist public sphere and a broader public sphere are, at least in part, mutually constitutive (Hartley 1996: 69). Building on this, Hartley and McKee (2000) point out that Indigenous people are not mere passive recipients of representation, but active and effective participants in media production, and that this contributes to the public contestation of notions of Indigeneity. This is an important point, and one that is increasingly relevant in light of the dramatic and effective take-up and mobilisation of digital platforms by Indigenous media activists.

Nevertheless, the utility of Hartley and McKee's model is compromised by an overly idealised set of claims regarding the 'dialogic' space of the public sphere. In conceiving this space as dialogic, Hartley and McKee draw on anthropologist Fred Myers's analysis of Pintupi meetings as being geared primarily toward the achievement of consensus, and assert that media increasingly play a similar role, as a means via which understanding of Indigeneity is increasingly developed and contributory to collective Indigenous and non-Indigenous identity (2000: 83). Here, the conception of 'dialogue' is underpinned by a claim that media are increasingly moving towards a progressive and inclusive public sphere: an 'evolutionary' process they view as inherent to a 'logic of democratic equivalence'. Hartley has argued elsewhere this logic is inherent to modernity, and progressively fulfilled in the shift toward a 'postmodern' commercial media environment (Hartley 1996, 1999). This also forms the foundation of Hartley and McKee's theorisation and reading of the 'Indigenous public sphere':

Political institutions are evolving in which commercial organizations are taking responsibility for democratic practice. Public participation is much higher and more enthusiastic in 'commercial democracy' than in the formal mechanics of representative politics (Hartley and McKee 2000, p4).

This reading has several problems. Firstly, as McCallum and Waller argue, it is not supported by Hartley and McKee's own analysis of media materials, which provides 'as much evidence for the dominance in media reporting of discourses of 'correction and protection' of Indigenous people as it does for the celebratory outlook for Indigenous self-expression' (2017, in press). Such a contradiction can be resolved, in circular fashion, by simply referring back to the premise of evolutionary modernity, such that the evidence is presented as a remnant product 
of a prior modernist regime of news that has yet to be fully expunged (Hartley and McKee 2000: 207). Secondly, Hartley and McKee's approach discounts critical consideration of the legacies of colonial racism and its contemporary manifestations, as such legacies are apparently on the way to being overcome by modernity's inherent teleo-logic. It also discounts consideration of how political and (particularly) commercial influences might contribute to the reproduction of discourses of Indigeneity and Indigenous issues as inherently and inevitably problematic and intractable, in ways that limit rather than enable engagement with Indigenous voices (Fforde et al 2013, Brough 1999). Thirdly, the 'evolutionary' model proposed not only overrides the need to support arguments by reference to evidence, but also undermines the need for intervention, or political struggle. The Indigenous public sphere is already established, and insofar as it is currently inadequate, such issues will be resolved both through a 'logic of democratic equivalence'. Ultimately, what is presented as an historical process is, in reality, a rather ahistorical (and entirely theoretical) set of claims that provide a ground for an asserted narrative of progress toward a dialogic, egalitarian ideal.

For Michael Meadows (2005), by contrast, the Indigenous public sphere is conceived as a space that derives from a lack of adequate representation in mainstream media, such that "many Indigenous people are turning their backs on mainstream media and engaging in their own forms of cultural production" (2005: 37). In contrast to Hartley and McKee's claims regarding an increasingly representative Indigenous public sphere that emerges through 'dialogue' between Indigenous and non-Indigenous Australia, Meadows proposes a conception of Indigenous public spheres as cultural sites for specifically Indigenous identities and voices to engage in dialogues that support the maintenance and expression of specific identities, and provide vehicles through which problematic representation in mainstream media can be contested:

[R]ather than adopting the idea of a single, all-encompassing public sphere, we should think in terms of a series, of the existence of parallel and overlapping public spheres spaces where participants with similar cultural backgrounds engage in activities of importance to them...Although they develop in close proximity to - and with a great deal of influence from - mainstream society, they should be seen as discrete formations that exist in a unique context as the product of contestation with the mainstream public sphere' (Meadows 2005: 37-38; emphasis added)

While Meadows's definition of the Indigenous public sphere does not absolutely contradict that of Hartley and McKee, it is nevertheless markedly different. As noted above, Hartley and McKee refer to definitions of Indigeneity being produced and circulated between Indigenous and non-Indigenous media spaces, particularly as the latter facilitate spaces for inclusive and egalitarian 'dialogue'. Meadows, on the other hand, conceives the Indigenous public sphere as, vitally, both distinct from and a product of contest with the mainstream. It is conceived as a space of identity and position formation that allows participants 'to formulate their own discursive styles and formulate their own positions that are then brought to the wider public sphere' (2005: 38). For Meadows, Indigenous public spheres exist as resistant responses to the inadequacies of mainstream media representation that he has elsewhere documented (Meadows 2001), as well as mechanisms for the persistence of Indigenous self-determination through communicative practices.

In contrast to Hartley and McKee, Meadows's model is more attentive to the ways in which representations of Indigeneity are structured by historical and contemporary disparities of power. Arguably, however, Meadows's claim that Indigenous public spheres can exist as 'discrete formations' despite the influence of mainstream society nevertheless presents an overly idealised model for understanding cultural 'resistance'. Folker Hanusch has suggested that 'Indigenous media are almost always a response to the dominant culture's media treatment of Indigenous people' $(2013,953)$. If this statement exaggerates the point, it nevertheless calls for recognition of how discussions of Indigenous identities and issues are often structured by, as well as resistant to, the limiting terms of non-Indigenous discourses, debates and representations. This is to say that, in both their direct exposure to mainstream media discourses and through the indirect influence these exert on wider public debates and 
public policy, Indigenous people are subject to (as well as being subjects who produce) various cultural discourses and texts that provide (variable) resources for understanding Indigenous identities, issues and concerns. In this respect, although Meadows's emphasis on the agency of Indigenous people and the degree to which Indigenous media practices embody cultural selfdetermination is important, the characterisation of Indigenous public spheres as 'discrete formations' may be overly idealised.

Arguably, too, both accounts are 'idealised' in another sense, insofar as the adoption of the public sphere discourse itself tends, by implication, to position the problem of representation through an image of speech and dialogue, centring on the Indigenous and non-Indigenous participants themselves (although, it should be acknowledged, Meadows's wider focus on community media as resources that facilitate speech goes beyond this). One consequence of this is a continued tendency to approach 'publics' as either a body of people and/or as a range of representations, without further consideration of the broader relations in which both people and representations are implicated. This, it may be argued, is in part a legacy of the adoption of the Habermasian concept of the public sphere, in which the 'space' of media tends to be metaphorically positioned as an expanded version of eighteenth century coffee houses and salons. To counter this tendency, in the next section we focus on the more materialist approach to public representation suggested by Bruno Latour's conception of 'making things public' (2005), and how this has been suggestively taken up by recent media scholarship that focuses on public representation as produced by, and implicated in, a broader field of relationships.

\section{Public Assemblages}

Recent work concerned to develop an expanded horizon for understanding and analysing publics has been informed by the take-up of Actor Network Theory (ANT) (Hawkins 2013, Anderson 2013, Anderson and Kreiss 2013). Rather than focus simply on human actors and what they say (or, alternatively, political-economic structures and what they do), ANT analyses draw on a wider consideration of how publics are formed and facilitated through the dynamic relations between a wide array of material 'things'. This approach is broader than seeing 'media' as mere secondary conduits for 'speech' or economic and political 'power'. It focuses on how media provide a heading for a complex and dynamic assemblage of human and nonhuman things. This is to say that media, as they have historically existed and transformed, exist as a pluralistic network of institutions, practitioners, technologies, discourses, practices, formats and heterogeneous relationships (with media owners, advertisers, state funders, regulators, sources and users) that collectively influence its various forms at any given time, and over its history. As Anderson and Kreiss argue, understanding the nature of public life involves taking into account the ways in which such assemblages have been historically constructed and transformed through the interactions (to draw on Latour's terminology) of the various actors and actants that constitute them:

$[\mathrm{T}] \mathrm{o}$ understand power and reform social institutions, and even uproot them, requires attention not just to theories of participation, deliberation and the public sphere, but the socio-technical engineering of democratic publics and the cultural presuppositions that guide it. (Anderson and Kreiss 2013: 380)

This theoretical approach to understanding publics invites a potentially wide array of analytical approaches, ranging from a macro-level focus on the various relations that contribute to public-making, to micro-level consideration of the impacts of particular developments within this field of relations - such as, for example, shifts in legal and regulatory frameworks, or the impact of a particular media platform and its affordances. The important contribution it makes, however, is its reconnection of considerations of democratic communication (and the democratic shortcomings and inequalities that structure the field) with the material relations that structure it. Returning to public debates surrounding public representation of Indigenous people and issues, we can now consider the intersections and divergences of various cultural and material influences. These include the continued impact of news values that tend to focus on 'race' as a site of social conflict (Bell 1997); focus on and construct 'events'; and tend to 
preference the perspective of social authorities (particularly government sources) (McCallum et al 2012). It is also important to consider the particular influence of institutional goals and the degree to which outlets are structured by different forms of market appeal that result in distinct editorial positions and practices. In this respect, market dynamics, and the degree to which these facilitate and constrain the market strategies of particular actors and institutions, serve as forces that materially enable and constrain public life, alongside state initiatives such as investment in media content initiatives (public and community media) and content regulation.

Alongside such influences, the discursive practices of governmental and non-governmental sources, and the particular ways in which these work to create media agendas to further public and political agendas by appealing to media predilections, also play a constitutive role in shaping public agendas and representations. The representation of Indigenous Australia is also a matter of great interest to private actors that use public relations and sponsorship to further their interests and manage their reputations, as well as exert influence over the nature of policies relating to Indigenous Australia such as those on land use and land rights.

In addition to these political, economic and media influences, a range of broader factors serves as material influences on representation. What technologies exist and are used to produce and circulate representations, and what are their affordances and constraints? To what extent have powerful and influential figures (such as journalists) acquired a cultural competence in reporting on Indigenous Australia? (McCallum, Waller and Meadows, 2012; Waller 2012). What understanding do they bring to that practice? What training have they undertaken that directly relates to such reporting, if any? To what extent do both journalists and audience-users rely on, and reproduce, inherited cultural tropes and narratives that serve to inform the stories they tell and how they are told? How far do such tropes and stories diverge and/or converge to provide a coherent and shared, or contested and multi-vocal range of representations?

Such questions take us beyond theoretical debates surrounding representation and the degree to which media support a 'genuine' public sphere, which is the point. Ultimately, a consideration of public discourse must consider how speech, representation and dialogue are facilitated and constrained by the relations that make "public(s)" and how they are constituted through them. In his case study analysis of the changing nature of news production and news products in the Philadelphia region, Anderson (2013) has referred to the relationship between 'assemblages' of material relationships, and the shifting 'ecologies' of news institutions and practices. Consideration of how such assemblages and ecologies contribute to 'public-making' does not negate a consideration of questions such as 'who speaks?' and 'who is heard?'. Rather, it is to focus on how such issues are imbricated in a particular, historical and mutable set of relationships. Having provided this brief overview of this field of relationships as it relates to Indigenous representation, we turn now to consider some recent work that has considered the role that the emergence of digital platforms has contributed to it.

\section{Media Ecologies and the Problem of Listening}

In the context of Indigenous representation in Australia, the problem of understanding the implications of networked digital media platforms for voice and listening has been taken up by the recent work of Dreher, McCallum and Waller (2016), which focuses on how the shifting media landscape provides opportunities for Indigenous people to gain a voice in policy debates. They also look at whether such opportunities enable actual political participation, and what potential constraints might limit opportunities for such voices to be heard (2016: 25). A number of key observations, concepts and prior findings inform this work. Observationally, they begin by noting the considerable proliferation of Indigenous outlets, practices and voices that have emerged in recent years. Many of these have been facilitated by the networked, participatory affordances of social media platforms, and their capacities of connection and networking content across local spheres, thereby creating new possibilities of connecting Indigenous voices, perspectives and debates. Such initiatives include blogs such as Celeste Liddle's 'Rantings of an Aboriginal Feminist'; the Deadly Bloggers site 
(www.deadlybloggers.com), which is a network/site that provides access to a range of Indigenous-authored blogs; and @IndigenousX, a Twitter-based initiative run by Indigenous culture advocate Luke Pearson, which operates as an outlet for debate and dissemination of diverse perspectives through a rotation of Indigenous commentators and topics on a weekly basis (Sweet et al 2013). @IndigenousX has also developed a strong relationship with the mainstream media outlet Guardian Australia, enabling both increased publicity and, at key moments, opportunities to reach a considerably wider audience.

The @IndigenousX relationship with Guardian Australia is also an example of shifts in the ecology of Australian mainstream news. Launched in 2013, Guardian Australia is a web-only local edition of the well-established British-based news organisation. It is a distinct new editorial presence in the highly concentrated Australian media marketplace, previously dominated by News Corporation and Fairfax Media. Notably, Guardian Australia has sought to challenge The Australian as the predominant site through which Indigenous-related events and issues are covered. Such developments are positioned by Dreher, McCallum and Waller as significant additions to what they characterise as Australia's media ecology:

Indigenous participatory media in Australia belong to a media ecology that incorporates mainstream media reporting about Indigenous people and issues; a government-funded and supported Indigenous communication sector, including the national Indigenous television network NITV; community newspapers, radio and online platforms, organizational and advocacy publications, as well as social media hubs, networks and citizen media producers. (2016: 28)

Transformations in this media ecology have, undoubtedly, been shaped in part by opportunities afforded by networked digital media technologies and social media platforms which have expanded the potential for Indigenous voices to gain a degree of media participation. However, Dreher, McCallum and Waller are concerned to investigate the degree to which increased media participation translates into increased political participation, an issue that brings us to the conceptual aspect of their work. An important issue is whether the emergence of digital platforms and practices of Indigenous participatory media have enabled such voices to contribute to shaping policy agendas. To consider this, Dreher, McCallum and Waller draw on the work of Carpentier (2011), who makes a distinction between a 'minimalist' definition of participation centred on access to infrastructures of media production and dissemination, and a 'maximalist' definition which refers to participation in processes of political decision-making. Previous work focused on Indigenous policy found that policymaking practices were, to a large extent, 'mediatised': that is, were increasingly targeted towards, and responsive to, the agendas, logics and routines of mainstream media outlets (McCallum et al 2012, Waller 2013). One consequence of this, following Carpentier's model, is that whether Indigenous participation is 'minimalist' or 'maximalist' depends to a large degree on how far a wide range of Indigenous voices gain access to mainstream media. This, as Dreher, McCallum and Waller note, is consistent with a conceptual shift in recent years from focusing on a politics of voice and who has opportunities to speak, to the problem of 'listening', which centres on the equally, if not more crucial, problem of which voices are heard in mediatised policy debates. This, they argue, 'shifts some of the focus and responsibility for democratic outcomes from marginalized voices and onto the conventions, institutions and practices that shape who and what can be heard in an increasingly mediatized policy-making environment' (Dreher, McCallum and Waller 2016: 28).

In addressing the problem of how far maximalist political participation (policy influence) has been enhanced by the emergence of participatory media, their findings are mixed. If such influence is to be achieved, it relies on how far mainstream media serve to 'amplify' a range of Indigenous perspectives and concerns, as opposed to a narrow range of established, dominant Indigenous voices in discussions of events and issues, and in the establishment of media agendas.

To a large extent, it remains the case that mainstream media act as a constraint on the capacity for Indigenous voices to be heard, as they tend to continue to focus on a narrow range of 
favoured and well-resourced voices that dominate media coverage and news agenda-setting. Nevertheless, they also found that on occasions, particular examples of activist campaigning were able to shift agendas in ways that - at least temporarily - enabled new voices and perspectives to enter into the dominant public sphere. A striking example of this was provided by @IndigenousX's intervention in the mediatised public debate over constitutional recognition for Australia's First Nations people. The debate had largely been dominated by the well-funded 'Recognise' campaign, a campaign that had received large-scale political and business support, and had been bolstered by the predominance of select Indigenous political figures such as Noel Pearson and Warren Mundine. Despite this, a range of Indigenous voices had raised concerns that the campaign for constitutional recognition served as a basis for narrowing agendas surrounding Indigenous rights to land and genuine treaty negotiations. After Recognise released a poll which suggested 75 per cent of all Australians and 87 per cent of Indigenous Australians supported recognition, @IndigenousX conducted an alternative poll, which found that a much smaller proportion of Indigenous people supported the constitutional reform agenda. @IndigenousX in collaboration with Indigenous blogger Celeste Liddle then reported on the findings of its poll on the IndigenousX website and distributed the story via the @IndigenousX Twitter account. The question of which poll was more accurately representative was less significant than the effect of the intervention by @IndigenousX. Because these disparate polls highlighted newsworthy aspects of conflict and controversy, and appealed to the established media interest in reporting on quantitative measures of public opinion, this poll soon became a news story that was amplified by a range of traditional and non-traditional outlets, including independent news website New Matilda, the Guardian Australia and the more mainstream ABC radio. In so doing, the intervention opened a space for constitutional recognition to be rendered as a matter of public controversy and debate, thus temporarily creating media space for a wider range of voices and perspectives to gain representation.

What is particularly useful about Dreher, McCallum and Waller's framework is that it enables consideration of how both enabling potentials and constraints on participation are linked to an abiding, but also changing, media ecology. This media ecology shapes, and is shaped by, shifting technological, institutional and political relationships. These relationships represent an inherited historical and contemporary assemblage that gives rise to forms of patterned representation, persistent inequalities of access, and presents continued structural constraints on the capacity for a wide range of Indigenous voices to be amplified and heard. At the same time, transformations in these relationships, with the emergence of new players and infrastructures, may serve to disrupt and potentially to transform these relationships. This may, on particular occasions and/or over time, work to reconfigure these relationships in ways that may enable such constraints to be, at least partially, overcome.

\section{Wakul App: Facilitating Political Participation Through Amplification}

As outlined above, the problem of 'voice', 'listening' and 'participation' relates not only to a willingness for media outlets to host Indigenous voices and to listen to and amplify existing perspectives, but to how relatively limited or enhanced infrastructures of voice and listening are produced by technologically, institutionally and politically structured relationships through which processes of 'public representation' occur. Over the last decade, there have been two major developments that, while not entirely restructuring the field, have nevertheless contributed to a certain restructuring of those relationships. The first of these is the emergence of new institutional actors that have served to challenge and, at least partially, transform the space of Indigenous representation. These have included new social media platforms and businesses, such as Facebook and Twitter, and new media players such as Guardian Australia. Social media platforms have enabled an augmentation of the space of community media representation, through the provision of new infrastructures for the hosting and dissemination of voice, while new media players have sought to include distinctive forms of Indigenous representation as part of their editorial and market strategies. The second development, 
related to the first, is a proliferation of Indigenous media initiatives that have taken up and used new platforms to produce representations, have used digital platforms to network Indigenous voices (both through social media initiatives such as @IndigenousX and digital broadcast media such as NITV), and have used such platforms to gain increased exposure in mainstream media. In both cases, the emergence of digital networked communication tools and infrastructures has been vital to these developments.

As we have seen, however, how far such developments produce 'maximal' levels of participation is dependent on how they interrelate with other aspects of an existing network of relationships. The simple existence of digital tools and platforms and new media initiatives does not, for example, result in a wholesale transformation in 'news values' that structure mainstream news. Nor does it automatically follow that the potential of digital communication platforms to provide mainstream journalists with access to a wider range of sources means that they will access them, or even know about them. Journalists working to deadlines are usually time poor, which contributes to a tendency to rely on and reproduce already-existing story frames and established, easily accessed sources. Such factors both condition and delimit the potential for new developments to exert a transformative influence. Bearing this in mind, the Centre for Advancing Journalism (CAJ) at the University of Melbourne has developed a piece of infrastructure that seeks to make a modest intervention into this network of relationships.

The genesis of this intervention began with the collation of a preliminary dataset of 150 Indigenous news sources with a view to amplifying their output to infiltrate Australia's dominant media systems, following the successful example of @IndigenousX. This dataset includes well-established legacy print media and broadcast entities, and also new digitallyenabled media, including social media channels that are breaking news and distributing original content across diverse geographic locations and demographics. This collation was part of a larger Civic Impact of Journalism project which aimed to provide empirical evidence on the impact of journalism in Australia, and how this is changing (Simons, et al 2015). In this context, the construction of the database was preliminary work for a case-study based examination of the degree to which these developments in the field were allowing new forms of Indigenous media participation, and the implications of this for civic impact, particularly on policy processes. The methodology for the broader civic impact campaign conceives of 'impact' as a generic term, incorporating both reach and engagement, but going beyond those ideas to encompass the reactions of institutional players, including governments and policy makers, and also how users are applying news and information in their personal and civic lives (Simons et al 2015, Clark 2010). The preliminary dataset, and the amount of Indigenous media participation that quickly became apparent, exposed the need for a more advanced methodology to collecting data for such a diverse range of news sources, and the potential to create a valuable public resource.

As noted above, for the potential impact of Indigenous use of new media to be maximized, amplification is key (McCallum and Waller 2015). Yet, as with the challenges faced by news media more broadly, Indigenous outlets are adversely affected by audience fragmentation which makes it harder to gather a large audience for any one piece of media content (Simons 2010, Simons 2013, Given 2003). The challenge faced by Indigenous news media is to find a 'centralised' or 'aggregated' audience, and also 'bridge' Indigenous perspectives and stories into mainstream news media more directly - in order to achieve the amplification of its intervention, on which maximalist participation in terms of impact and influence relies. With this challenge in mind, in $2016 \mathrm{CAJ}$ began to develop a prototype system designed to facilitate the amplification of First Nations voices and improve representation both within the connected counter-public of Indigenous public spheres and the broader mainstream public sphere. The Wakul App (meaning 'One' in traditional Gathang language) is an advanced piece of software infrastructure principally tailored to the needs of connecting Indigenous communities through the technology they are using. The design of Wakul App has been implemented using a spiral development process, which enables us to keep Indigenous advisors engaged in the system design throughout the development period. This consultative approach will continue in future stages of development and has informed our decision to release the source code under an open 
source licence. In 2018 the GitHub repositories containing the code will be made public to promote code re-use and collaboration and adaptation from the public.

There are two key components to the Wakul App: a data layer and the mobile application. The data layer stores rich and fine-grained data of Indigenous news outlets, news content and social media content and uses a combination of different database management systems to cater for different user needs. The result is a document-oriented and heterogeneous archive of news outlets. Each news source is attributed with unique geospatial data, such as: broadcast reach of radio stations; circulation area of print media; and analyses of location-enabled social networks. This geospatial data can then be combined with aggregated census statistics enabling, for example, the ability to determine which specific issues are affecting searchrelevant Indigenous communities and how far such issues are receiving attention in local, regional or national media. In addition, through a process known as 'Twitter harvesting', the Wakul app can provide data for social network source and sentiment analysis.

Wakul App allows users, communities, researchers, the media and the broader public to meaningfully interact with the collected data. The app contains a rich feature set including news feeds, a First Nations interactive map and a news source directory. The news feed updates with local stories as the user seeks information on geographic locations. The news feed also highlights trending topics within Indigenous networks, determined via real-time analysis of news articles and social media activity. The emphasis of the algorithm is placed on discovering what issues matter to Indigenous users and communities rather than what is being distributed by mainstream media outlets. A directory of the Indigenous news outlets is also accessible, enabling users to retrieve the details and contact information, promoting direct communication between Indigenous users and the wider media. CAJ is currently in discussion with media organisations about ways in which the Wakul App can be used within the news industry to amplify Indigenous perspectives and improve representation. These might include allowing mainstream journalists to "spot" issues being discussed by Indigenous Australians, assisting editorial executives to identify and recruit Indigenous citizen-activists and promising journalists, and/or allowing the production of an aggregated page of Indigenous news and views, to be hosted on a mainstream news media website.

In developing the Wakul App, our concerns are twofold. Firstly, and most directly, the project is informed by the CAJ mission of 'advancing journalism' by addressing an area of identified need. As discussed above, a common finding of work addressing Indigenous media representation is that a relatively narrow range of stories is linked to the dominance of selected, established voices in mainstream media. In recent years, however, transformations in media technologies and markets have facilitated new initiatives within the actor networks through which Indigenous public representation occurs. In light of this, the Wakul App provides a tool via which a trend toward amplifying voice via digital networks might be furthered through the networked tracking and aggregation of Indigenous debates. It will also, importantly, provide a tool through which non-Indigenous users, including professional journalists, can gain a closer understanding of Indigenous concerns and debates, as well as identify and potentially access actors that are articulating such concerns. Secondly, we are concerned to understand the impact of this initiative, by understanding how the Wakul App interfaces with, and intervenes in, the field of relationships in which it is taken up and used. In approaching this problem, however, we are both concerned to avoid a simplistic technological determinism, and mindful of the problems of 'effects' approaches. Furthermore, we do not assume that diagnoses of a failure to 'listen' in mainstream media are likely to be resolved by the development of an app. For example, while the Wakul App may assist time-pressed journalists in efficiently tracking Indigenous debates and in identifying a wider range of voices, the tendency among journalists to rely on a narrow range of sources does not stem only from a lack of access to other voices. Rather, as this paper has suggested, to consider the agential power exerted by the Wakul App as one thing within a wider network, it is necessary to consider this in relation to an existing and shifting field of relations, and the wider range of agencies that constitute the field of Indigenous representation. 


\section{Conclusion}

This article has sought to provide a reconsideration, and ultimately a reconceptualization, of framings of Indigenous media representation. To this end, it identified two distinct, and largely contrasting, approaches. On one hand, Hartley and McKee's model of the Indigenous public sphere as a product of all representations (Indigenous and non-Indigenous) was considered. A strength of this model is that it enables consideration of not only how Indigenous discussions and debates were shaped by a wider public sphere, but also the significant role played by Indigenous voices in this broader space. A weakness, however, was that a framing of the public sphere as a progressively inclusive 'dialogue' provided little basis for engaging with both how and why Indigenous voices continue to be largely marginalized in mainstream media debate, and representations of Indigenous people and issues continue to position both as sites of deficit and intractable problems. By contrast, Meadows approach defines the Indigenous public sphere as multiple, discrete sites of self-determining communication, through which Indigenous people exchange perspectives and maintain voice. These alternative spaces are seen as existing as resistant responses to the perceived inadequacies and injustices of mainstream media representation. While a particular strength of this model was its emphasis on self-determination and resistance, a potential shortcoming was that its model of discrete formations may overemphasise the degree to which sites and practices of Indigenous communication are entirely discrete - either from each other, or from the influence of wider processes of public representation. In addition, in both cases it was noted that an effect of the Habermasian model tended to reproduce a model of public representation as conversations writ large, a framing that tends by implication to exclude a wider consideration of the broader relations through which public representation occurs, and publics are thus 'made' on an ongoing basis.

An alternative approach, underpinned by ANT, focuses instead on the network of material (political) relations through which forms of public representation occur, and the effects for both representations of Indigenous Australia and the degree to which Indigenous voices are amplified. Here a review of recent work highlights how the digital initiatives both offer potentialities for increased amplification of Indigenous voices through their disrupting the settled nature of relations, but such potentials are also subject to constraint. 'Listening', we argue, is not simply a matter of altering the consciousness of journalists or of white Australia, but rather is a longer game that involves effecting transformations in an assemblage of relations that has been historically structured through inequalities of power, the violence of settlement, as well as Indigenous resistance and self-determination. While such a complex undertaking is unlikely to be radically affected by any 'magic bullet', our discussion of the Wakul App, as an initiative aiming to make a modest contribution to re-assemblage, is informed by our understandings that the existing relations that support public representation are products of history, albeit one that is deeply embedded in this public assemblage. Nevertheless, historically formed relations are subject to the effects of historical change, and we can therefore both expect and hope for their transformation.

\section{References}

Anderson, A. A., Brossard, D, Scheufele, D. A., Xenos, M. A. and Ladwig, P. (2014). "The 'Nasty Effect': Online Incivility and Risk Perceptions of Emerging Technologies.” Journal of Computer-Mediated Communication 19: 373-387. doi: 10.1111/jcc4.12009

Anderson, C.W. (2013) Rebuilding The News: Metropolitan Journalism In The Digital Age. Philadelphia: Temple University Press.

Anderson, C.W. \& Kreiss, D. (2013) "Black Boxes as Capacities for and Constraints on Action: Electoral Politics, Journalism, and Devices of Representation”. Qual Sociol 36:365382

Bell, P. (1997), “News Values, Race and 'The Hanson Debate' in Australian Media”, Asia Pacific Media Educator. 2:38-47. 
Broersma, M. \& Graham, T. (2012) "Social media as beat: tweets as a news source during the 2010 British and Dutch elections”, Journalism Practice, 6(3), pp.403-419.

Brough, M. (1999), "A Lost Cause? Representations of Aboriginal and Torres Strait Islander Health in Australian Newspapers", Australian Journal of Communication, 26(2):8998.

Bruns, A. (2008) "Life Beyond the Public Sphere: Towards a Networked Model for Political Deliberation." Information Polity 13(1-2):65-79.

Bruns, A. (2008) "The Active Audience: transforming journalism from gatekeeping to gatewatching", Making Online News: The Ethnography of New Media Production, Paterson, C. and Domingo, D. (Eds.) 171-184. New York: Peter Lang.

Carlson, B. \& Frazer, R. (2015) “It's like going to a cemetery and lighting a candle”, AlterNative: An International Journal of Indigenous Peoples, 11(3):211-224.

Castells, M. (2009) Communication power. Oxford; New York: Oxford University Press.

Carpentier, N. (2011) "The concept of participation: If they have access and interact do they really participate?” CM-časopis za upravljanje komuniciranjem, 6(21):13-36.

Cottle, S. (2000) "Introduction - Media Research and Ethnic Minorities: Mapping the field" in S. Cottle (ed) Ethnic Minorities and the Media.1-30. Maidenhead; Philadelphia: Open University Press.

Cunneen, C. (1992) 'Racial Stereotypes Kill', in K. Eggerking and D. Plater (eds), Signposts: A Guide to Reporting Aboriginal, Torres Strait Islander and Ethnic Affairs, Sydney: Australian Centre for Independent Journalism, pp. 24-26.

Davis, M. \& G. Williams. (2015) Everything You Need To Know About the Referendum to Recognise Indigenous Australians, New South Publishing: University of NSW, Sydney.

Dreher, T. McCallum, K \& Waller, L. (2016) “Indigenous voices and mediatized policy-making in the digital age", Information, Communication \& Society. 19(1):23-39

Due, C. \& Riggs, D. (2011) Representations of Indigenous Australians in the Mainstream News Media, Brisbane: Post Pressed.

Dunlop, T. (2013) The New Front Page: new media and the rise of the audience. Scribe Publications.

Dutton, W. H. (2008) "The Fifth Estate Emerging Through the Network of Networks." Prometheus. 27(1):1-15.

Eley, G. (1992) "Nations, Publics, and Political Cultures: Placing Habermas in the Nineteenth Century”, Habermas and the Public Sphere. Calhoun. C (Ed.) 289-339. Cambridge, Mass and London, England: MIT Press.

Ewart, J. (1997) “The Scabsuckers: Regional Journalists' Representation of Indigenous Australians", Asia Pacific Media Educator, 3:108-17.

Fforde, C. Bamblett, L. Lovett, R. Gorringe, S. \& Fogarty, B. (2013) "Discourse, Deficit and Identity: Aboriginality, the Race Paradigm and the Language of Representation in Contemporary Australia”, Media International Australia, 149:162-73.

Flew, T. (2009) "Democracy, participation and convergent media: Case studies in contemporary online news journalism in Australia." Communication, Politics \& Culture 42(2):87-109.

Fraser, N. (1992) "Rethinking the Public Sphere: A Contribution to the Critique of Actually Existing Democracy", Habermas and the Public Sphere. 109-42. Cambridge, Mass and London, England: MIT Press. 
Gans, H.J. (1999) “Deciding What's News”, News: A Reader, Tumbler, H. (Ed.) 235-246. New York: Oxford University Press.

Gitlin, T. (1998) “Public Sphere or Public Sphericules?” , Media, Ritual and Identity, Liebes,T. Curren J, Katz, E, (Eds.) 168-174. New York: Routledge.

Given, J (2003) Turning off the Television: Broadcasting's Uncertain Future, UNSW Press.

Gladwell, M. \& Shirky, C. (2011) "From innovation to revolution: Do social media make protests possible?”, Foreign Affairs 90(2):153.

Golding, P. Philip, R. \& Courtney, E. (1979) Making the news. Longman Publishing Group.

Graham, T, \& Wright, S. (2015) "A Tale of Two Stories from 'Below the Line' Comment Fields at the Guardian.” The International Journal of Press/Politics. 20(3): 317-338.

Habermas, J. (1989) The Structural Transformation of the Public Sphere: An Inquiry into a Category of Bourgeois Society. Trans. Burger,T \& Lawrence, F. Cambridge, Mass.: MIT Press.

Hanusch, F. (2013) "Charting a Theoretical Framework for Examining Indigenous Journalism Culture”, Media International Australia. 149:82-91.

Hartley, J. (1996) Popular Reality: Journalism, Modernity, Popular Culture. London: Arnold.

Hartley, J. \& McKee, A. (2000) The Indigenous Public Sphere: The Reporting and Reception of Aboriginal Issues in the Australian Media. Oxford: Oxford University Press.

Hawkins, G. (2013). "Enacting public value on the ABC's $Q$ \& A." Media International Australia, 146:82-92.

Jakobowicz, A. Goodall, H. Martin, J.A. Mitchell, T. Randall, L. \& Seneviratne, K. (1994) Racism, Ethnicity and the Media, Sydney: Allen \& Unwin.

Jericho, G. (2012) The rise of the fifth estate: Social media and blogging in Australian politics. Scribe Publications.

Latour, B. (2005) "From Realpolitik to Dingpolitik, or How to Make Things Public." Making Things Public: Atmospheres of Democracy. Latour, B. \& Weibel, P. (Eds.) Cambridge, Mass.: MIT Press.

Lewis, S.C. (2012) "The tension between professional control and open participation: Journalism and its boundaries.” Information, Communication \& Society 15(6):836-866.

Lumby, B. (2011) “Cyber-Indigeneity: Urban Indigenous Identity on Facebook”, Australian Journal of Indigenous Education, 39 (Supplement):68-75.

Meadows, M. (2001) Voices in the Wilderness: Images of Aboriginal People in the Australian Media, Westport, CT: Greenwood Press.

Meadows, M. (2005) “Journalism and Indigenous Public Spheres”, Pacific Journalism Review, 11(1): 36-41.

McCallum, K. (2011) "Journalism and Indigenous Health Policy", Australian Aboriginal Studies 2: 21-31.

McCallum, K. Waller, L. \& Meadows, M. (2012) "Raising the Volume: Indigenous Voices in News Media and Policy”, Media International Australia, 142:101-11.

McCallum, K. Waller, L. Meadows, M. Dunne-Breen, M. \& Reid, H. (2012) The Media and Indigenous Policy: How News Media Reporting and Mediatized Practice Impact on Indigenous Policy, Canberra: University of Canberra.

McCallum, K. \&Waller, L. (2013) "The Intervention of Media Power in Indigenous Policymaking”, Media International Australia 149:139-149. 
McCallum, K. \& Waller, L. (in press, 2017) The dynamics of news media and Indigenous policy in Australia. Bristol: Intellect.

McNair Ingenuity Research (2014) Media Usage Amongst Aboriginal and Torres Strait Islander People. Available at: http://mcnair.com.au/wp-content/uploads/MediaUsage-amongst-Aboriginal-and-Torres-Strait-Islander-People-McNai....pdf [accessed 20 May 2016].

Newman, N. Dutton, W.H. \& Blank, G. (2012) "Social media in the changing ecology of news: The fourth and fifth estates in Britain", International Journal of Internet Science, 7(1):6-22.

Paradies, Y. Harris, R. \& Anderson, I. (2008) The Impact of Racism on Indigenous Health in Australia and Aotearoa: Towards a Research Agenda, Discussion Paper No. 4, Darwin: Cooperative Research Centre for Aboriginal Health.

Shirky, C. (2011) "The political power of social media: Technology, the public sphere, and political change." Foreign Affairs Jan/Feb

Simons, M. (2010) The Content Makers - Understanding the Media in Australia. Penguin, Melbourne.

Simons, M. (2013) Journalism at the Crossroads. Scribe, Melbourne.

Simons, M. Tiffen, R., Hendrie, D. Carson, A. Sullivan, H. Muller, D. \& McNair, B. (2016) "Understanding the civic impact of journalism: A realistic evaluation perspective”, Journalism Studies. 1-15.

Shoemaker, P.J. Vos, T.P. \& Reese, S.D., (2009) “Journalists as gatekeepers”, The handbook of journalism studies Wahl-Jorgensen, K. \& Hanitach, T. (Eds.) 73-88 Routledge: New York \& London.

Stoneham, M.J. Goodman, J. \& Daube, M. (2014) "The Portrayal of Indigenous Health in Selected Australian Media”, The International Indigenous Policy Journal, 5(1), Available at http://ir.lib.uwo.ca/iipj/vol5/iss1/5_accessed 14 September 2016].

Sweet, M. Pearson, L. \& Dudgeon, P. (2013) “@IndigenousX: A case study of community-led innovation in digital media”, Media International Australia. 149:104-111.

Thompson, J. B. (1995) The Media and Modernity: A Social Theory of Media. Cambridge: Polity Press, 1995.

Waller, L. (2012) “Journalists, 'Remote' Indigenous Australia and Cultural Competence”, The Media and Indigenous Policy: How News Media Reporting and Mediatized Practice Impact on Indigenous Policy McCallum, K. Meadows, M. Waller, L. Dunne-Breen, M. \& Reid, H (Eds), 51-59, Canberra: University of Canberra.

Waller, L. Dreher, T. \& McCallum, K. (2015) "The Listening Key: Unlocking the Democratic Potential of Indigenous Participatory Media”, Media International Australia, 154: 5766.

Waters, R. Tindall N. \& Morton, T.S. (2010) "Media catching and the journalist-public relations practitioner relationship: How social media are changing the practice of media relations." Journal of Public Relations Research 22(3):241-264.

Wright, S. \& Street, J. (2007) "Democracy, deliberation and design: the case of online discussion forums", New media \& society 9(5):849-869.

Wright, S. (2012) "Politics as usual? Revolution, normalization and a new agenda for online deliberation”, New Media \& Society, 14(2):244-261.

Copyright: (C) 2017 Latimore, Nolan, Simons \& Khan. This is an open-access article distributed under the terms of the Creative Commons Attribution-NonCommercial 3.0 
Australia License, which permits non-commercial use, distribution, and reproduction in any medium, provided the original author and AJIS are credited.

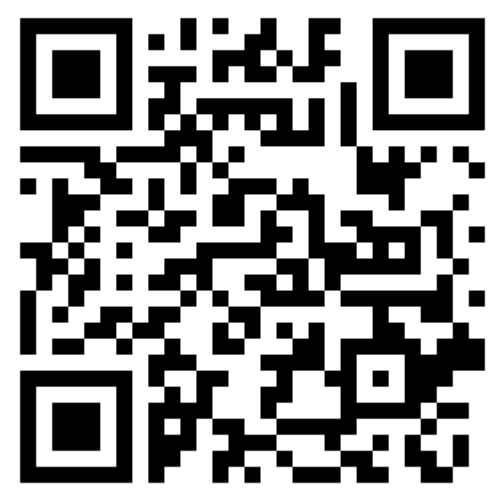

